\title{
Karaçam testere talaşının polipropilen kompozitlerin mekanik özelliklerine etkisi
}

\author{
Nasır Narlığlu ${ }^{1 *}$, Nihat Sami Çetin² ${ }^{2}$ Mehmet Hakkı Alma ${ }^{3}$
}

$\ddot{\mathbf{O z}}$

Günümüzde çevreye olan duyarlılıktaki artış ile birlikte atık maddelerin geri dönüştürülebilme konuları üzerine araştırmalar yapılmaktadır. Bu çalışmada, polipropilen matrise ilave edilen farklı oranlardaki karaçam testere talaşından elde edilen kompozit malzemelerin mekanik özelliklerindeki değişiklikler incelenmiştir. Kompozit malzeme üretimi için odun unu ve polipropilen çift burgulu ekstruder ile karıştırılarak pellet elde edilmiştir. Elde edilen pelletlerden sıcak pres kalıplama tekniği ile 250×250×2 mm ebatlarında kompozit levhalar üretilmiştir. Daha sonra, üretilen kompozit levhaların ASTM standartlarına göre çekme, eğilme ve darbe direnci testleri yapılmıştır. Mekanik test sonuçlarına göre en yüksek çekme direnci değeri \%10 odun unu ilaveli kompozit örneğinde, en yüksek eğilme direnci ise \%50 odun unu ilaveli kompozit örneğinde tespit edilmiştir. Ayrıca kompozitler arasında en yüksek darbe direnci, \%20 odun unu ilaveli kompozit örneğinde elde edilmiştir.

Anahtar kelimeler: karaçam, testere talaşı, PP, kompozit, mekanik özellikler

\section{Effect of black pine sawdust on the mechanical properties of polypropylene composites}

\author{
Nasır Narlıoglu ${ }^{1 *}$, Nihat Sami Çetin² ${ }^{2}$ Mehmet Hakkı Alma ${ }^{3}$
}

\begin{abstract}
Today, studies on the recycling of waste materials increasingly gaining importance and increasing with the growing sensitivity to the environment. In this study, the changes in the mechanical properties of composite materials produced by adding the black pine sawdust with the polypropylene matrix at different ratios were investigated. For the production of composite materials, pellets were obtained by mixing wood flour and polypropylene with twin-screw extruder. The obtained pellets were molded into composite boards in $250 \mathrm{x} 250 \mathrm{x}$ $2 \mathrm{~mm}$ dimensions with hot press molding technique. Then tensile, bending and impact resistance tests of composite boards produced were carried out according to ASTM standards. According to the results of the mechanical tests; the highest tensile strength value was found for the composite sample of $10 \%$ wood flour loaded composite, while the highest bending strength was found for the composite with 50\% wood flour. In addition, the highest impact resistance was obtained for the $20 \%$ wood flour added sample among all composites.
\end{abstract}

Keywords: black pine, sawdust, PP, composites, mechanical properties 


\section{Giriș}

Kompozitler, farklı kimyasal ve fiziksel özelliklere sahip iki veya daha fazla maddeden oluşan, iyi tanımlanmış bir yapıya sahip, günlük hayatımızın her yerinde bulunan ve hayatımızın ayrılmaz bir parçası haline gelmiş malzemelerdir. Kompozitlerdeki matrise takviye edilmesi için, 20. yüzyılın ortalarına kadar doğal liflerden faydalanılmıştır. 1950'den beri, havacılık, ulaşım ve inşaat gibi alanlarda daha güçlü, daha sert ve hafif kompozitler için artan bir talep oluşmuştur (Hull ve Clyne, 1996; Mallick, 2007; Kumar ve ark., 2011). Sentetik lifler ile takviye edilmiş kompozitlerin aksine OPK (Odun Plastik Kompozit) gibi doğal liflerle güçlendirilmiş kompozitler, özellikle düşük maliyetli malzeme üretiminde oldukça ilgi uyandırmışlardır. OPK'lerin kapı-pencere doğraması, profiller, zemin ve diş cephe kaplaması gibi esasen yarı yapısal ya da yapısal olmayan uygulama alanlarında kullanılabildikleri belirtilmiştir (Pritchard, 2004; Stark ve Matuana, 2004; Smith ve Wolcott, 2006; Klyosov, 2007). Biyokompozitlerin kendine özgü yüksek mekanik direnç, akustik özellikleri, düşük üretim maliyetleri, biyo-bozunabilir olmaları, aşırı sıcaklık değişikliği altında sabit formda kalmaları sebebiyle artırılmış yolcu güvenliği ve ağırlık azalışı sonucu enerji tüketiminde düşüşe sebep olmaları gibi avantajları bu kompoziterin otomobil parçaları üretiminde tercih edilme sebepleri arasında olduğu belirtilmiştir (Ashori, 2008).

Takviye edici doğal lifler veya odun unu, OPK'lerdeki ana yükü taşıma bileşenidir. Bu bileşenler kompozit malzemelere uygulanan mekanik kuvvet altında, bükülmeye ve kırılmaya karşı direncin yanı sıra yüksek mukavemet ve sertlik sağlarlar. Bitki liflerinin birtakım olumlu özellikleri ve düşük maliyetli oluşu, onları doğal lif takviyeli kompozit malzeme üretiminde sentetik takviye edici liflere göre daha cazip hale getirmiştir. Örneğin; keten ve kenevir lifleri, standart cam liflerine kıyasla \%40 daha ucuzdur (Ashori, 2008, Bhaskar ve ark., 2012).

Termoplastik polimerler ısıtıldığında polimer zincirleri ayrışmakta ve yeniden işleme tabi tutulmalarını sağlamak için birbirleri üzerinde kaymalar görülmektedir. Yüksek yoğunluklu polietilen (YYPE), polipropilen (PP) ve polivinil klorür (PVC), doğal lif takviyeli kompozitlerde kullanılan en yaygın termoplastik polimerlerdir (Klyosov, 2007). YYPE, doğal lif takviyeli kompozitlerde kullanılan termoplastiklerin büyük çoğunluğunu oluşturur (\%83), bunu sirasiyla PP (\%9) ve PVC (\%7) takip eder (Caulfield ve ark., 2005). Odunun termal bozulma sıcaklığının $180-200{ }^{\circ} \mathrm{C}$ altındaki sıcaklıklarda olduğu için termoplastikler, doğal lif takviyeli kompozitlerin üretimi için oldukça caziptir. Ayrıca termoplastikler, ahşap esaslı malzemelerin şekillendirilmesinde kullanılan makinelerde ve kesici aletlerde kesilebilir, vidalanabilir ve çeşitli şekiller verilebilirler (Schwarzkopf ve Burnard, 2016).

İğne yapraklı ağaç tomruklarının kereste ve son ürün haline getirilmesinde genel olarak \%30-40 arasında odun veya kereste artığı ortaya çıkmaktadır. Artıklar az gelişmiş ve gelişmekte olan ülkelerde genellikle enerji üretimi veya 1sınma amaçlı yakılırken, gelişmiş ülkelerde ise entegre tesislerde yonga levha, lif levha veya kağıt hamuru üretiminde değerlendirilmektedir (Sofuoğlu ve Kurtoğlu, 2006). Diğer taraftan yonga ve lif levha üretimi ve kullanımı esnasında yaklaşık olarak ortaya çıkan atık yüzdesinin \%5-25 arasında olduğu bilinmektedir (Bromhead, 2003).

Günümüzde çevreye olan duyarlılıktaki artış ile birlikte hammaddelerin verimli kullanımı ve atık maddelerin geri dönüştürülebilme olanakları üzerine araştırmalar yapılmaktadır. Bu atık maddelerden biri de önemli bir atık potansiyeline sahip olan orman endüstrisi atıklarıdır. Bu çalışmada kereste veya mobilya fabrikalarında açığa çıkan testere talaşı atıklarının PP polimer matrise ilavesi ile kompozit malzeme üretimi amaçlanmıştır. 


\section{Materyal ve Metot}

\subsection{Materyal}

$\mathrm{Bu}$ çalışmada kompozit malzeme üretimi için lignoselülozik dolgu maddesi olarak karaçam (Pinus nigra Arn. subsp. pallasiana (Lamb.) Holmboe) odun unu kullanılmıştır. Çalışmada kullanılan odun unu, Kahramanmaraş ili küçük sanayi sitesi mobilya atölyelerinden temin edilmiş karaçam tomruk veya kerestesinin işlenmesi esnasında açığa çıkan testere talaşı atıklarıdır. Ayrıca bu çalışmada polimer matris olarak polipropilen (PP; PETKİM MH-220N) kullanılmıştır.

\subsection{Metot}

Karaçam odunu testere talaşı öncelikle sarsak elekte elenerek 80 mesh parçacık boyutu üstü (177-250 $\mu \mathrm{m})$ kısımlar kompozit malzeme üretiminde kullanılmak üzere tasnif edilmiştir. Kompozit malzeme üretimi için eleme işlemleri sonrası tasnif edilen lignoselülozik maddeler, yapısında bulunan rutubetin uzaklaştırılması için bir gün boyunca $103 \pm 2{ }^{\circ} \mathrm{C}$ 'ye ayarlı firında tam kuru ağırlığa gelinciye kadar kurutulmuştur. Daha sonra kurutulan odun unu toplam kompozit ağırlığının \%10-50 oranında, PP polimer matrise ilave edilerek kompozit üretimi gerçekleştirilmiştir. Kompozitlerin karışım oranları Tablo 1'de verilmiştir.

Tablo 1. Kompozit örneklerinin karışım oranları

\begin{tabular}{|l|l|l|}
\hline Örnekler & Lignoselülozik (\%) & Polimer (\%) \\
\hline PP & - & PP (100) \\
\hline KC1 & Karaçam odunu (10) & PP (90) \\
\hline KC2 & Karaçam odunu (20) & PP (80) \\
\hline KC3 & Karaçam odunu (30) & PP (70) \\
\hline KC4 & Karaçam odunu (40) & PP (60) \\
\hline KC5 & Karaçam odunu (50) & PP (50) \\
\hline
\end{tabular}

$\mathrm{Bu}$ çalışmada kompozit malzeme üretimi için ilk önce ekstruder yöntemi ile pellet üretimi gerçekleştirilmiştir. Bu kapsamda ekstruder sıcaklık profili Tablo 2'de verilen ve vida hızı 50 devir/dk'ya ayarlı GÜRDAL marka çift burgulu ekstruder kullanılarak 2-3 mm arası boyutlarda pelletler üretilmiştir. Ekstrüzyon sonrası elde edilen pelletler kompozit malzeme üretiminde kullanılan özel alüminyum kalıp içerisine yerleştirilerek, $190^{\circ} \mathrm{C}$ 'ye ayarlı CARVER marka hidrolik preste 9 ton $/ \mathrm{m}^{2}$ basınç altında 15 dakika bekletilerek 250x250x2 mm ebatlarında kompozit levha formuna dönüştürülmüsstür. Kompozit levhaların elde edilmesinde ASTM D4703 standartlarına uyulmuştur.

Tablo 2. Çift burgulu ekstruder kovan sıcaklık profili

\begin{tabular}{|c|c|c|c|c|c|c|c|}
\hline \multicolumn{8}{|c|}{ Ekstruder kovan sıcaklığ $\left({ }^{\circ} \mathrm{C}\right)$} \\
\hline 1.Giriş Bölgesi & 2.Bölge & 3. Bölge & 4. Bölge & 5 . Bölge & 6. Bölge & 7. Bölge & 8.Ç1k1ş bölgesi \\
\hline 40 & 100 & 130 & 160 & 170 & 170 & 180 & 185 \\
\hline
\end{tabular}

Kompozitlerin mekanik özelliklerini belirlemek için eğilme, çekme ve darbe direnci testleri yapılmıştır. Eğilme direnci testi ASTM D790 standardına göre 150x13x2 mm boyutlarındaki 10 adet test örneği kullanılarak, çekme direnci testi ASTM D638 standardına göre (dog bone shape) hazırlanan 10 adet test örneği kullanılarak yapılmıştır. Ayrıca darbe direnci testi $64 \times 13 \times 2 \mathrm{~mm}$ ebatlarında hazırlanan ve üzerine çentik aç1lan 10 adet test örneği ile ASTM D256 standardına göre yapılmıştır. Hazırlanan test örnekleri teste tabi tutulmadan önce bir hafta boyunca $\% 60 \pm 5$ bağ 1 nem ve $22 \pm 3{ }^{\circ} \mathrm{C}$ sıcaklığa ayarlı iklimlendirme kabininde şartlandırılmıştır. 


\section{Bulgular ve Tartışma}

Şekil 1'de karaçam odun unu ilaveli kompozitlerin çekme direnci değerleri verilmiştir. Karaçam odun unu ilaveli kompozitler arasında en yüksek çekme direnci değeri $28.10 \mathrm{MPa}$ ile \%10 odun unu ilaveli kompozit örneğinde tespit edilmiştir. Diğer yandan en düşük çekme direnci değeri ise $16.57 \mathrm{MPa}$ ile \%50 odun unu ilaveli kompozit örneğinde tespit edilmiştir.

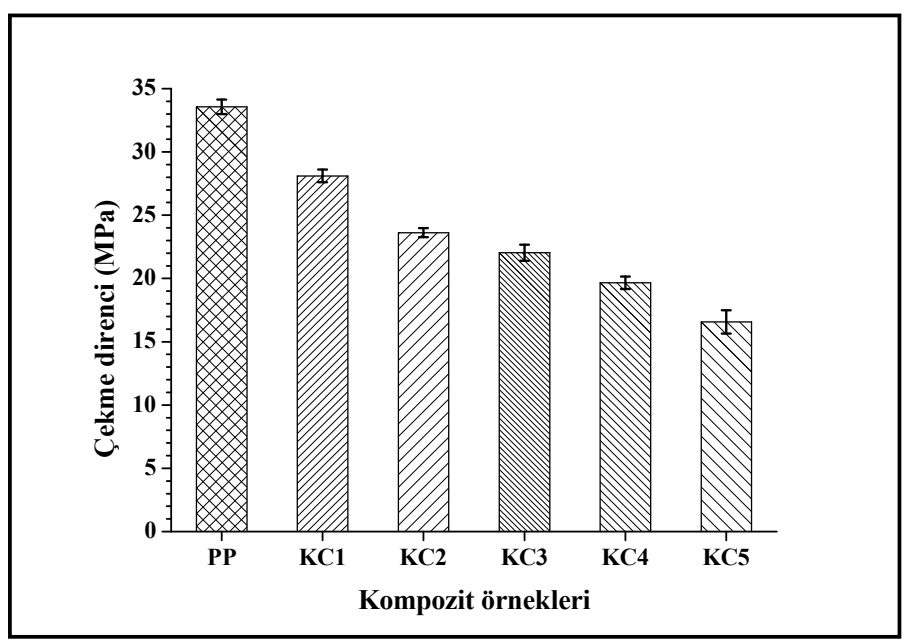

Şekil 1. Karaçam odun unu ilaveli PP kompozitlerin çekme direnci değerleri

Genel olarak doğal lif takviyeli kompozitlerin çekme mukavemetlerinin, kompozit karışımına ilave edilen lif oranındaki artış ile kademeli olarak düştügü rapor edilmiştir (Bengtsson ve ark., 2007; Khoathane ve ark., 2008; Ku ve ark., 2011). Altuntaş ve ark., (2017) tarafından yapılan çalışmada, polimer matrise ilave edilen odun lifi oranı artışı ile kompozitlerin çekme direnci değerlerinde azalma olduğu belirtilmiştir. Bu çalışmada saf PP polimer matrisin çekme direnci değeri $33.56 \mathrm{MPa}$ olarak belirlenirken, polimer matrise ilave edilen odun unu katılım oranı artışı ile kompozitlerin çekme direnci değerlerinde azalma görülmüştür.

Karaçam odun unu ilaveli PP kompozitlerin eğilme direnci değerleri Şekil 2'de verilmiştir. Kompozitler arasında en yüksek eğilme direnci değerleri $\% 40$ ve $\% 50$ odun unu ilaveli kompozit örneklerinde sırasıyla $42.29 \mathrm{MPa}$ ve $42.53 \mathrm{MPa}$ olarak tespit edilmiştir. Diğer taraftan en düşük eğilme direnci değeri,\%10 odun unu ilaveli kompozit örneğinde 37.27 $\mathrm{MPa}$ olarak tespit edilirken, bu değer ile saf PP polimerin eğilme direnci değeri (37.42 $\mathrm{MPa})$ birbirine yakın değer sergilemiştir.

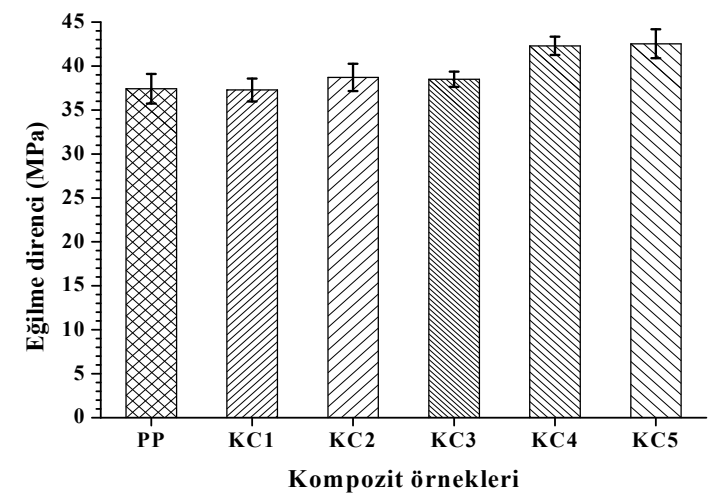

Şekil 2. Karaçam odun unu ilaveli PP kompozitlerin eğilme direnci değerleri 
Özmen ve ark., (2014) Orta Yoğunluklu Liflevha (MDF) tozunun PP’ye ilavesi ile yaptıkları çalışmada, polimere ilave edilen MDF tozu katılım oranı artışı ile kompozitlerin eğilme direnci ve elastikiyet modülü değerlerinde artış olduğunu bildirmişler. Diğer taraftan doğal lif ilaveli kompozitlerde lif katılım oranındaki artışa bağlı olarak kompozitlerin eğilme direnci değerlerinde ve elastikiyet modülü değerlerinde artış görüldüğü bazı araştırmacılar tarafindan rapor edilmiştir (Bengtsson ve ark., 2007; Basiji ve ark., 2010). Bu çalışmada polimer matrise ilave edilen odun unu katılım oranı artışı ile birlikte kompozitlerin eğilme direnci değerlerinde artış kaydedilmiştir.

Şekil 3'te Karaçam odun unu ilaveli PP kompozitlerin eğilmede elastikiyet modülü değerleri verilmiştir. Burada en yüksek eğilmede elastikiyet modülü değeri $2.72 \mathrm{GPa}$ ile \%50 odun unu ilaveli kompozit örneğinde görülürken, en düşük eğilmede elastikiyet modülü değeri ise $1.98 \mathrm{GPa}$ ile \%10 odun unu ilaveli kompozit örneğinde tespit edilmiştir. Genel olarak polimer matrise ilave edilen doğal liflerin katılım oranındaki artışla kompozitlerin elastikiyet modülü değerlerinde ilk önce artış daha sonra ise azalış görüldüğü belirtilmiştir. (Hajnalka ve ark., 2008; Khoathane ve ark., 2008). Şekil 3'te görüldüğü üzere polimer matrise ilave edilen odun unu katılımındaki artış ile kompozit malzemelerin eğilmede elastikiyet modülü değerlerinde artış görülmüştür.

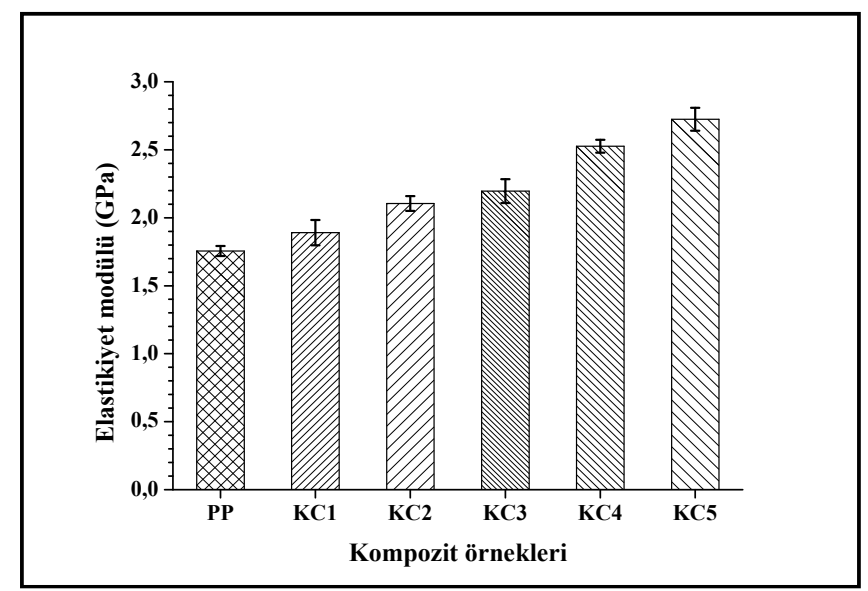

Şekil 3. Karaçam odun unu ilaveli PP kompozitlerin eğilmede elastikiyet modülü değerleri

Karaçam odun unu ilaveli PP kompozitlerin darbe direnci değerleri Şekil 4'te verilmiştir. Şekilde görüldüğü üzere polimer matrise odun unu ilavesiyle saf polimer matrise göre kompozitlerin darbe direnci değerinde azalma görülmüştür.

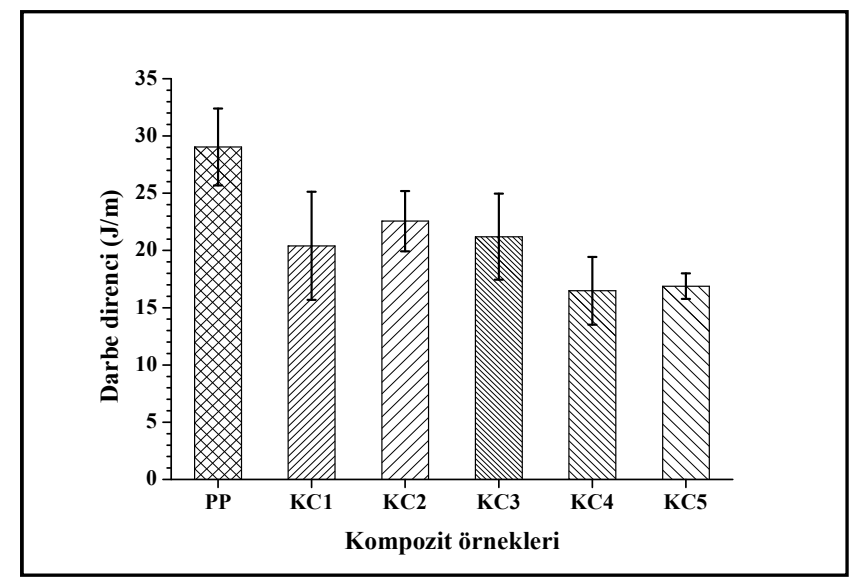

Şekil 4. Karaçam odun unu ilaveli PP kompozitlerin darbe direnci değerleri 
Burada saf PP polimer matrisin darbe direnci değeri $29.04 \mathrm{~J} / \mathrm{m}$ olarak kaydedilmiştir. Diğer taraftan odun unu ilaveli kompozitler arasında en yüksek darbe direnci değeri $22.56 \mathrm{~J} / \mathrm{m}$ değeri ile \%20 odun unu ilaveli kompozit örneğinde, en düşük darbe direnci değeri ise 16.48 $\mathrm{J} / \mathrm{m}$ ile \%40 odun unu ilaveli kompozit örneğinde tespit edilmiştir. Polimer matrise ilave edilen doğal liflerin kompozitlerin darbe direnci özelliklerine olumsuz etki yaptığı bazı çalışmalarda rapor edilmiştir (Basiji ve ark., 2010; Kumar ve ark., 2017).

\section{Sonuçlar}

Karaçam testere talaşının PP kompozitlerin mekanik özelliklerine etkisi adlı bu çalışmada;

- Karaçam odun ununun PP polimer matrise ilavesiyle elde edilen kompozitlerin çekme direnci değerlerinde giderek azalma kaydedilmiştir.

- Kompozit karışımındaki odun unu oranı artışı ile kompozitlerin eğilme direnci değerlerinde ve elastikiyet modülü değerlerinde artış görülmüştür.

- PP polimer matrisine ilave edilen odun unu ile kompozitlerin darbe direnci değerlerinde azalma görülürken, bu azalmanın odun unu oranı artışı ile doğrusal bir şekilde azaldığı görülmemiştir.

- Doğal lif ilaveli kompozitlerin kullanım alanlarının başında plastiğe alternatif ürünlerin kullanıldığı çeşitli kullanım yerleri (yer ve duvar döşemesi vd.) gelmektedir. Bu alanlarda kullanılacak ürünlerin ASTM D 6662'ye uygun olarak, eğilme direncinin en az 6.9 MPa ve eğilmede elastikiyet modülü değerinin ise yaklaşık $345 \mathrm{MPa}$ olması istenmektedir. Bu bakımdan bu çalışma kapsamında elde edilen karaçam odunu testere talaşı atığı ilaveli PP kompozitlerin çeşitli kullanım yerleri (kapı-pencere kasaları, yer ve duvar döşemeleri vb.) için uygun olduğu sonucuna ulaşılmıştır.

\section{Teșekkür}

$\mathrm{Bu}$ çalışma Kahramanmaraş Sütçü İmam Üniversitesi bilimsel araştırma projeleri yönetim birimi başkanlığı tarafından 2015/3-61D numaralı proje kapsamında desteklenmiştir.

\section{Kaynaklar}

Altuntaş, E., Yılmaz, E., \& Salan, T. (2017). Yüksek oranda lif dolgu maddesi kullanımının odun plastik kompozit malzemenin mekanik özellikleri üzerine etkisinin araştırılması. Turkish Journal of Forestry, 18(3), 258-263.

Ashori, A. (2008), Wood-plastic composites as promising green-composites for automotive industries. Bioresource Technology, 99(11), 4661-4667.

ASTM, D638. (2001), Standard test methods for tensile properties of plastics. American Society for Testing and Materials.

ASTM, D790. (2003), Standard test methods for flexural properties of unreinforced and reinforced plastics and electrical insulating materials. American Society for Testing and Materials.

ASTM, D256. (2005), Standard test methods for impact resistance of plastics and electrical insulating materials. American Society for Testing and Materials.

ASTM, D4703-10. (2010), Standard practice for compression molding thermoplastic 
materials into test specimens, plaques, or sheets. American Society for Testing and Materials.

Basiji, F., Safdari, V., Nourbakhsh, A., and Pilla, S. (2010), The effects of fiber length and fiber loading on the mechanical properties of wood-plastic (polypropylene) composites. Turkish Journal of Agriculture and Forestry, 34(3), 191-196.

Bengtsson, M., Le Baillif, M., and Oksman, K. (2007), Extrusion and mechanical properties of highly filled cellulose fibre-polypropylene composites. Composites Part A: Applied Science and Manufacturing, 38(8), 1922-1931.

Bhaskar, J., Haq, S., Pandey, A., and Srivastava, N. (2012), Evaluation of properties of propylene-pine wood plastic composite. Journal of Materials and Environmental Science, 3(3): 605-612.

Bromhead, A. (2003). Reducing wood waste in furniture manufacture. Fauna \& Flora International, Cambridge, UK.

Caulfield, D.F., Clemons, C., Jacobson, R.E., and Rowell, R.M. (2005), 13 Wood Thermoplastic Composites. Handbook of wood chemistry and wood composites: 365 .

Hargitai, H., Rácz, I., and Anandjiwala, R. D. (2008), Development of hemp fiber reinforced polypropylene composites. Journal of Thermoplastic Composite Materials, 21(2), 165174.

Hull, D., and Clyne, T. (1996), An introduction to composite materials. Cambridge University Press, UK, $326 \mathrm{~s}$.

Khoathane, M. C., Vorster, O. C., and Sadiku, E. R. (2008), Hemp fiber-reinforced 1pentene/polypropylene copolymer: the effect of fiber loading on the mechanical and thermal characteristics of the composites, Journal of Reinforced Plastics and Composites, 27(14), 1533-1544.

Klyosov, A.A. (2007), Wood-plastic composites. John Wiley \& Sons, Inc., Hoboken, New Jersey, 720 s.

Ku, H., Wang, H., Pattarachaiyakoop, N., and Trada, M. (2011), A review on the tensile properties of natural fiber reinforced polymer composites. Composites Part B: Engineering, 42(4), 856-873.

Kumar, R., Obrai, S., \& Sharma, A. (2011), Chemical modifications of natural fiber for composite material. Der Chemica Sinica, 2(4): 219-228.

Kumar, R., Singh, T., \& Singh, H. (2017), Effects of fiber type, weight percentage loading and fiber size on impact strength and hardness of wood and rice husk hybrid composite. International Journal of Materials Science, 12(3), 443-460.

Mallick, P.K. (2007), Fiber-reinforced composites: materials, manufacturing and design. CRC press, USA, $638 \mathrm{~s}$.

Özmen, N., Çetin, N., Narlığlu, N., Çavuş, V., \& Altuntaş, E. (2014). MDF atıklarının odun plastik kompozitlerin üretiminde değerlendirilmesi. Turkish Journal of Forestry, 15(1), 65-71.

Pritchard, G. (2004), Two technologies merge: wood plastic composites. Reinforced Plastics, 48(6): 26-29.

Schwarzkopf, M.J., and Burnard, M.D. (2016), Wood-Plastic Composites-Performance and 
environmental impacts. Environmental impacts of traditional and innovative forest-based bioproducts. Springer, pp. 19-43.

Smith, P.M., and Wolcott, M.P. (2006), Opportunities for wood/natural fiber-plastic composites in residential and industrial applications. Forest Products Journal, 56(3), 411 .

Sofuoğlu, S.D., and Kurtoğlu, A. (2006), Masif ağaç malzemenin işlenmesinde fire oranları. Dumlupinar Üniversitesi Fen Bilimleri Enstitüsü Dergisi, 11: 189-204.

Stark, N.M., and Matuana, L.M. (2004), Surface chemistry and mechanical property changes of wood-flour/high-density-polyethylene composites after accelerated weathering. Journal of Applied Polymer Science, 94(6), 2263-2273. 